\title{
Failure Analysis on Titen Proto-XX Car Chassis
}

\author{
Gaguk Jatisukamto*, Rika Dwi Hidayatul Qoryah, Santoso Mulyadi \\ Department of Mechanical Engineering, University of Jember, Indonesia \\ Jl Kalimantan 37, Jember, 68121 \\ *Corresponding author:gaguk.ft@unej.ac.id
}

\begin{abstract}
The car chassis as a skeleton supports all loads and is the most important component. Car chassis requirements must be rigid, twisting resistant, vibration resistant and resistant to fatigue. This study aims to find the cause of the failure of the Titen Proto-XX car chassis connection. The research methodology was conducted by testing the composition of materials and structural analysis using Ansys Workbench Release 15.0 software. The conclusion of the research is that the skeletal structure material uses Aluminum AA series 1 XXX with $\mathrm{Al}$ content greater than $99.5 \%$, the welding ability is low, causing a failure in the welded joint. The rivet connection failure is caused by the stress concentration in the rivet holes in the plates so that the connection crack propagation occurs.
\end{abstract}

Copyright @ 2019. Journal of Mechanical Engineering Science and Technology

All rights reserved

Keywords: Alumunium, chassis, rivet connection, Titen Proto, welding connection

\section{Introduction}

The electric car was first developed by Thomas Davenport and Robert Anderson around 1830. The first electric vehicle using a non-rechargeable battery. Its development is relatively slow when compared to oil-fueled vehicles. The reduced availability of fuel oil, encourages research on lightweight and strong chassis material, thereby saving battery energy [1]. The choice of lightweight chassis material is highly expected on condition that it has good mechanical properties and is expected to match or even exceed steel so the duration of battery charging can be extended. The Titen Proto-XX is one of the electric cars that use battery power as a source of energy and aluminium as a chassis material.

Automotive chassis requirements must be able to withstand the weight of the vehicle, hold dynamic loads, resist twisting, resist vibration and rigid [2]. Elastic deformation is still possible as long as it still meets the allowable tolerance. Aluminium and steel structures are generally used as automotive chassis materials because they have good mechanical properties, although the strength of aluminium is still below steel. The use of aluminium as an automotive component material for steel substitutes continues to be developed, due to various advantages in terms of corrosion resistance and relatively lightweight. The ratio of mechanical properties of aluminium to good weight can reduce $\mathrm{CO}_{2}$ emissions and improve engine efficiency [3]. Chassis weight affects the rolling resistance value of a vehicle. Reducing the weight of a vehicle will improve acceleration and improve braking characteristics [4].

The use of aluminium as a chassis must be careful analysis because the deformation and elastic strength of aluminium are still below the steel structure. Critical points that must get 
the main attention lies in the connection [5]. Alloy elements such as $\mathrm{Cu}, \mathrm{Zn}, \mathrm{Mn}, \mathrm{Mg}, \mathrm{Si}$ and $\mathrm{Li}$ greatly influence the grain boundary strengthening, precipitation hardening, and aluminium hardening work. The $\mathrm{Cu}$ element will reduce corrosion resistance and improve weldability, but increase the weight of aluminium [6]. The weldability of aluminium causes difficulties in the connection between elements of the chassis structure. In this case, the rivet connection is also an alternative choice. The rivet cross-section is able to withstand shear stresses, but plastic deformation and material failures often occur on plates which are joined with rivets, due to the stress concentration in the geometry discontinuity of the hole aperture [7].

This research was conducted to determine the causes of damage to the structure of the electric car Titen Proto-XX. In general, structural failures at electric car Titen Proto-XX often occur at structure joint that receives dynamic loads. This research is focused on structural materials, welded joints, rivet joints which receive critical loads

\section{Methods}

\section{Materials and Tools}

The material used is AA 1XXX series aluminium based on X-Ray Fluorescence (XRF) analysis. The composition of the chemical elements from XRF observations is listed in Table 1. The cross-section of a rectangular-shaped chassis with dimensions of $50 \times 25 \mathrm{~mm}$ and a plate thickness of $1 \mathrm{~mm}$. The design of the Titen Proto-XX car chassis has been using welded joints, but due to its low weldability, some connections use rivets, as shown in Figure 1. Some connections between truss use weld and rivet connections. Some connection frames among the trunk fail when welded. It can be avoide by using the rivets as the joint.

Table 1. Chemical composition of Aluminum AA 1XXX

\begin{tabular}{ccccc}
\hline Elements & $\mathrm{Fe}$ & $\mathrm{Cr}$ & $\mathrm{Ti}$ & $\mathrm{Al}$ \\
\hline$\%$ & 0,264 & 0,165 & 0,014 & balance \\
\hline
\end{tabular}
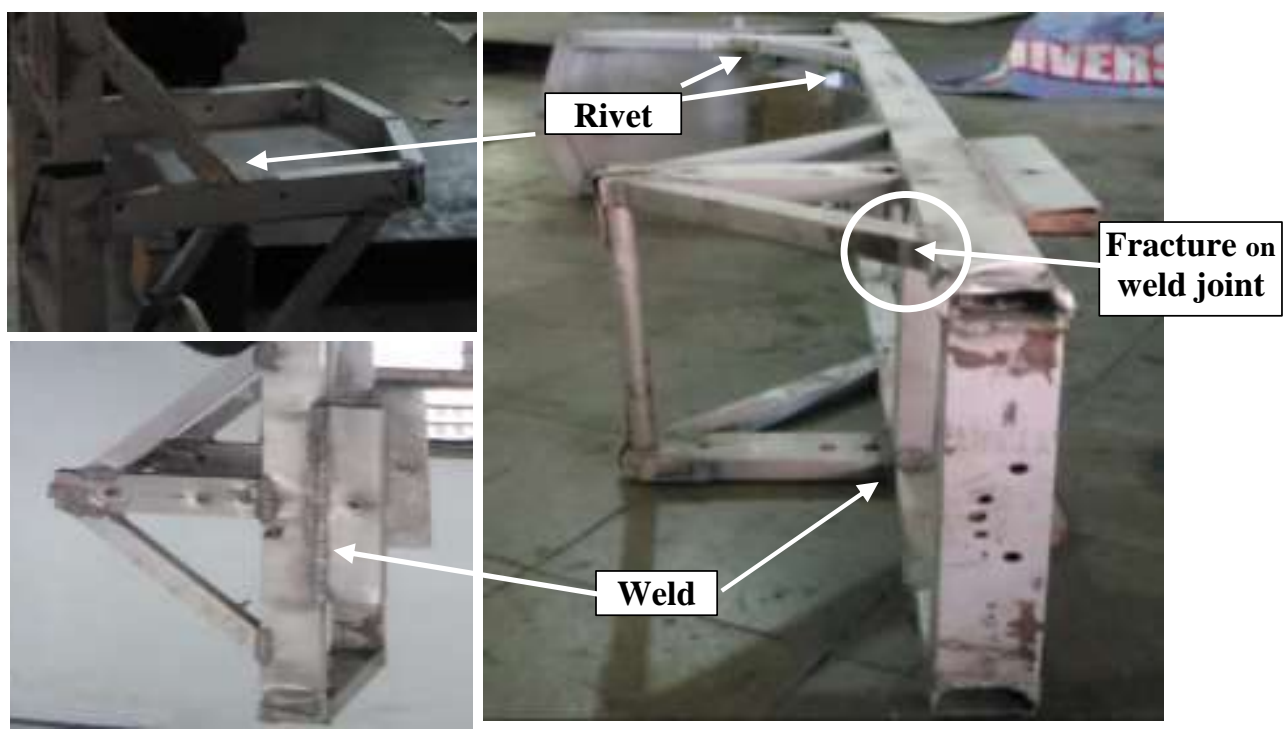

Fig. 1. Welding and rivet connections on the Proto-XX Titen Car 


\section{Procedure}

The research methodology is carried out through the stages that have been determined, as follows:

\section{A. Determination of location and type of support}

Figure 2 shows the type of fixed hinge on the Titen Proto-XX electric car.

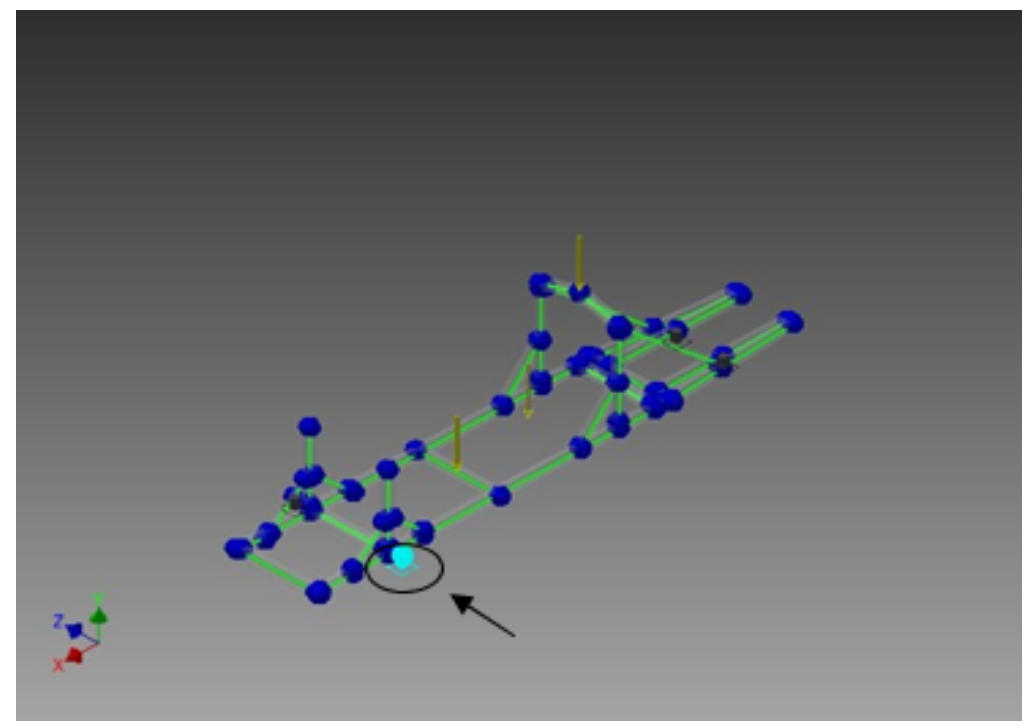

Fig. 2. Fixed pedestal position at 4 pedestal points

B. Determination of the loading position.

C. Loads are centered on the mainframe (driver load $=500 \mathrm{~N}$ ) and compressive loads imposed on the roll bar $(700 \mathrm{~N})$.

D. Centralized loading of frame $=500 \mathrm{~N}$, roll bar load load $=700 \mathrm{~N}$, battery centralized load $=200 \mathrm{~N}$ ) as shown in Figure 3.

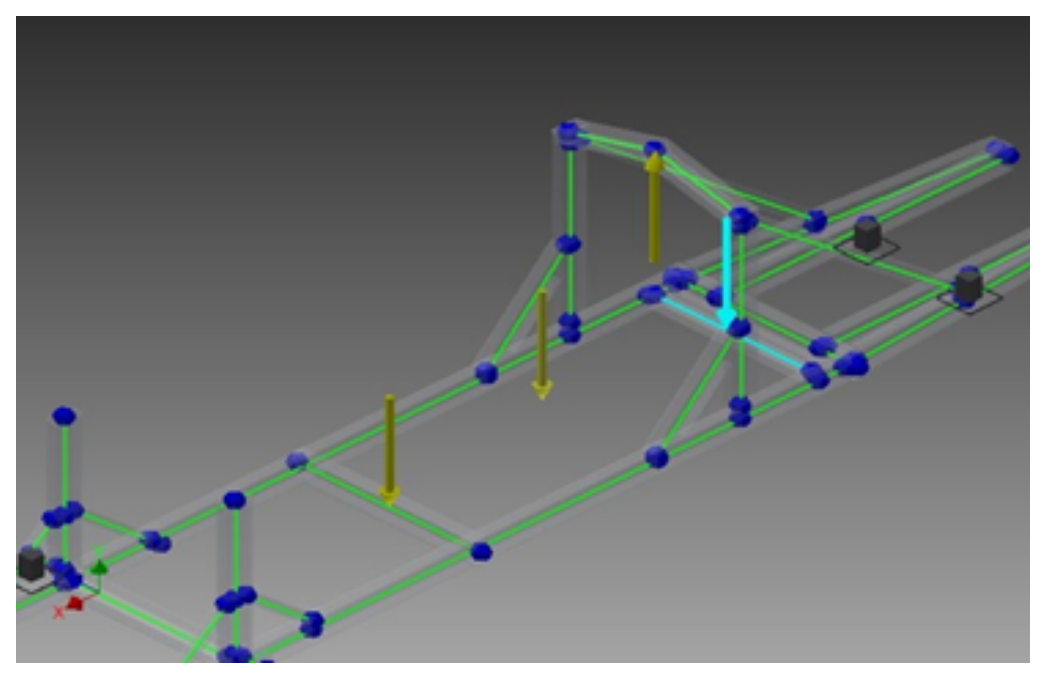

Fig. 3. Loading on mainframe and rollbar 
E. Input data

i. Chassis design on the Titen Proto-XX car using the inventor software using in Figure 4.
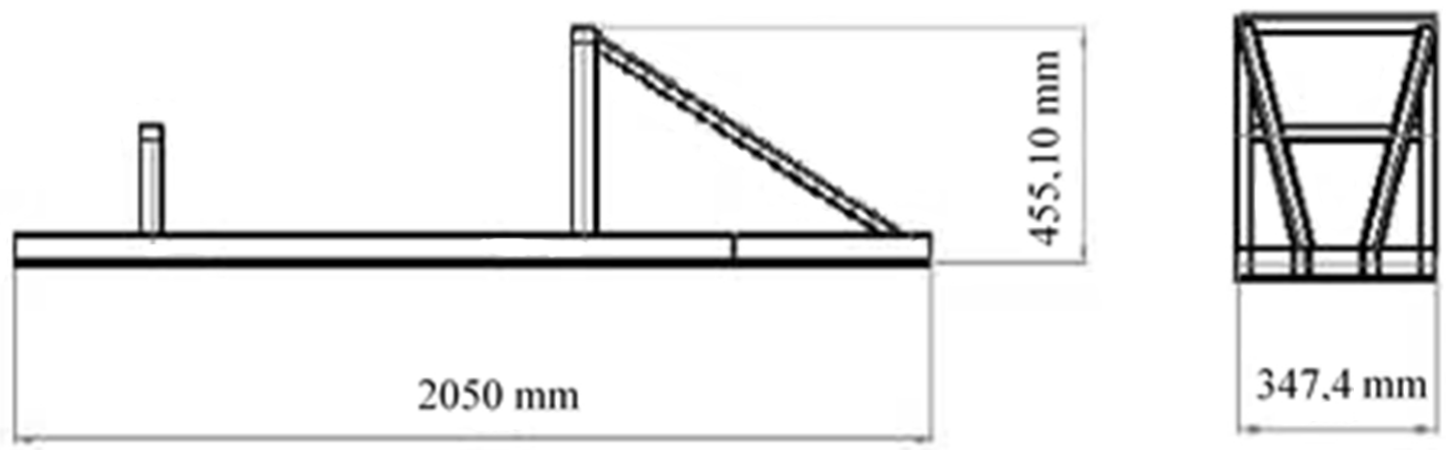

Fig. 4. 2D chassis of a Titen Proto-XX car

i i . Titen Proto car chassis material specifications.

The specifications of the Titen Proto-XX car chassis use Aluminum material as listed in Table 2.

Table 2. Specification of Aluminium AA 1 XXX

\begin{tabular}{lll}
\hline Properties & Value & Unit \\
\hline Mass Density $(\gamma)$ & 2.710 & $\mathrm{~g} / \mathrm{cm}^{3}$ \\
Yield Strength $(\sigma \mathrm{y})$ & 275.000 & $\mathrm{MPa}$ \\
Ultimate Tensile Strength $(\sigma \mathrm{t})$ & 310.000 & $\mathrm{MPa}$ \\
Young's Modulus $(\mathrm{E})$ & 68.900 & $\mathrm{GPa}$ \\
Poisson's Ratio $(v)$ & 0.330 & - \\
\hline
\end{tabular}

\section{Software}

Analysis of the loading and deformation of the Titen Protto-XX car chassis was carried out with the help of the 2015 Autodesk Inventor Professional Software and Ansys Workbench Release 15.0, each of which has functions according to Table 3.

Table 3. Software for the Analysis of the Structure of a Titans Proto Car Structure

\begin{tabular}{ll}
\hline \multicolumn{1}{c}{ Software } & \multicolumn{1}{c}{ Useful } \\
\hline $\begin{array}{l}\text { Autodesk Inventor } \\
\text { Profesional } 2015\end{array}$ & Software for technical drawing design \\
Ansys Workbench & $\begin{array}{l}\text { Software for analysis of material strength, deflection } \\
\text { and stress concentration in the chassis }\end{array}$ \\
\hline
\end{tabular}




\section{Results and Discussion}

Figure 5 shows the simulation results of loading and deformation on the Titen ProtoXX car chassis. Chassis loads include roll bar weights, passenger weights and battery weights. The red color is in the middle, indicating that the deformation is the largest. Real uneven road conditions cause dynamic loads in the form of impact, vibration and fatigue loads on the structure. Rigid structural design and improper material selection endanger the safety of passengers.
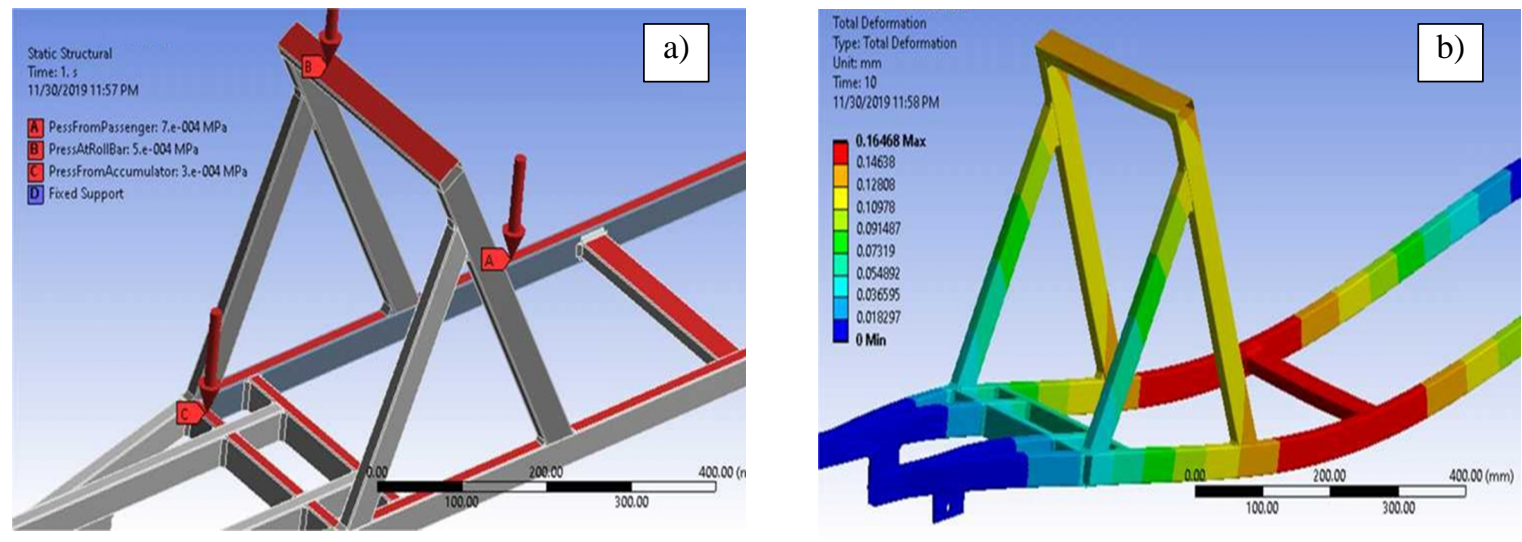

Fig. 5. Simulation of loading and deformation on Titen Proto-XX car chassis; a). Structural joints are assumed to be weld joints. b). The deformation plot structure of the chassis.

Analysis of Titen Proto-XX car chassis failure analysis is based on the material used and analysis of simulation results with the help of Ansys software. A detailed discussion of the causes of failure of the Titen Proto-XX car can be described as follows:

A. Failure due to material selection factors

The results of the chemical composition test with the XRF method obtained the conclusion that the material of the Titen Proto-XX car chassis is aluminium series one, namely AA $1 \mathrm{XXX}$. The most dominant main element is $\mathrm{Al}$, whose number is greater than 99.5\% (\% weight), while the rest is an impurity, which is shown in Table 1 . The weldability of aluminium AA $1 \mathrm{XXX}$ is very low. Aluminium has good weldability if the Al content is less than $94 \%$, where the best weldability is at the $\mathrm{Al}$ content of about $50 \%$ [8]. The use of aluminium AA $1 \mathrm{XXX}$ is the cause of cracks in the welded joint. The failure of the welding joint is due to improper preparation of the workpiece before it is welded. Dirt such as dust, oil, grease, and aluminium oxide must be removed before welding. Aluminium oxide should be removed first by brushing, scraping or blasting. For large-scale welding work, the removal of oxides should be done with chemicals, but it is constrained by the relatively expensive costs of the environmental impact produced. Chemicals for removing the oxide layer are $\mathrm{NaOH}$ and $\mathrm{HNO}_{3}[9]$.

\section{B. Rivet connection failure}

Connections between truss in some places also use rivets, as shown in Figure 6. Inaccurate cutting elements of the trunk element cause clearance between trunks when connected, causing greater deformation when the vehicle glides on the road. Chassis deformation will be even greater when the vehicle glides on the road, due to the influence of vibrations, impact loads, and uneven road contours. 


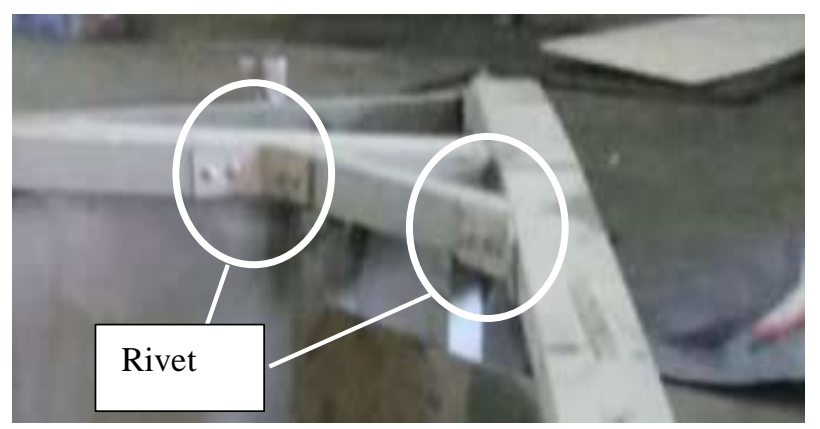

Fig. 6. Rivet connection on the Titen Proto-XX car chassis

Figure 7 shows the distance between rivet (rivet pitch) and the distance of rivet from the edge of the plate (edge distance) [3]. The position of the rivet hole greatly influences the fatigue life of the plate joints. A rivet hole is a form of plate geometry discontinuity, where the hole also apparently has an impact as a crack initiation. The movement of the car on the road will provide an external dynamic load that initiate the crack propagation. The end of the failure at the connection between the two plates is the material fail (fracture). Figure 8 shows a macro photo of a two-plate fatigue failure in Figure 7. The Fatigue Test results show that the closer the rivet is to the edge, the greater the fatigue failure will be (Figure 8a). The greater edge distance gives smaller fatigue damage, as shown in Figure 8 (b, c and d). The smaller the distance of the rivet from the edge of the plate will cause a greater distribution of stresses in the plate hole. The plate tears in Figure 8a show that the area experiences critical stress due to stress concentrations.

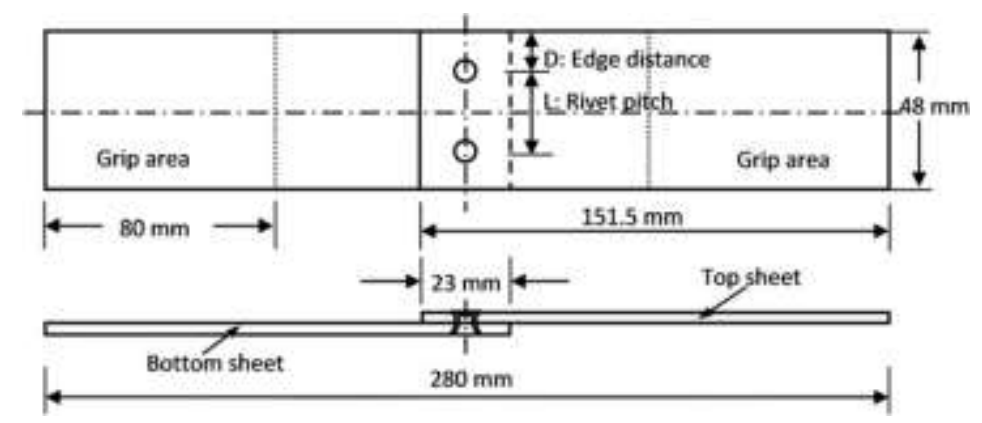

Fig. 7. Specimen geometry for lap shear tests [3]
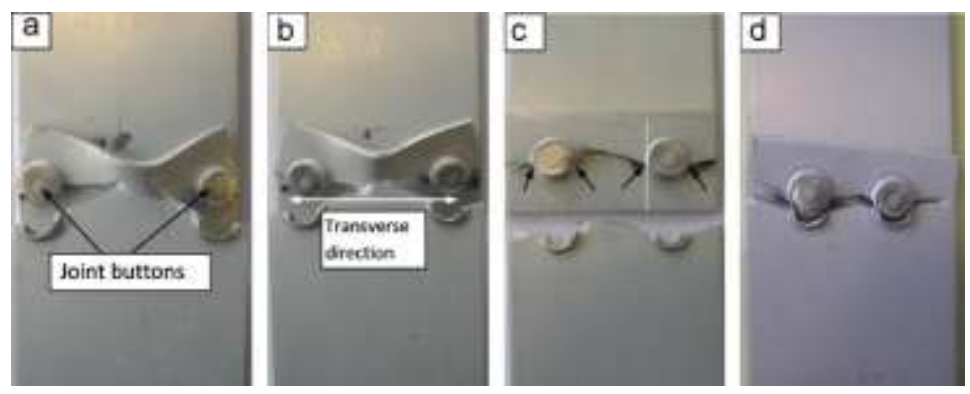

Fig. 8. Lap shear fatigue fracture interfaces of specimens tested at low load amplitudes, $1.35 \mathrm{kN}$ or $1.575 \mathrm{kN}$, for specimen with different edge distances: (a) $6 \mathrm{~mm}$, (b) $8 \mathrm{~mm}$, (c) $11.5 \mathrm{~mm}$ and (d) $14.5 \mathrm{~mm}[3]$ 
The discontinuity at the plate joints causes stress concentrations in the holes that initiate cracks, as shown in the bolt connection in Figure 9 [10]. The Von Mises yield stress distribution of single and double bolt joints that accept tensile loads shows different Von Mises voltage contours. A connection of two parallel bolt holes results in a greater Von Mises stress distribution when compared to a connection with one hole. The increasing number of holes will not necessarily improve the strength of the structure but can be the opposite. Figure $9 \mathrm{~b}$ illustrates that the red contour shows a greater critical load than just one connection hole.

a)
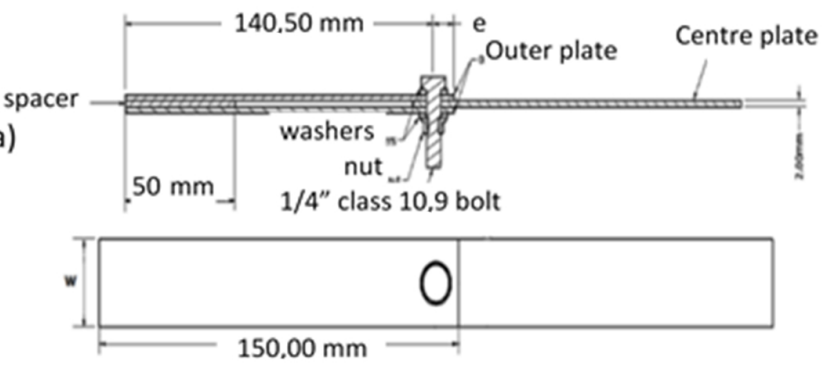

b)
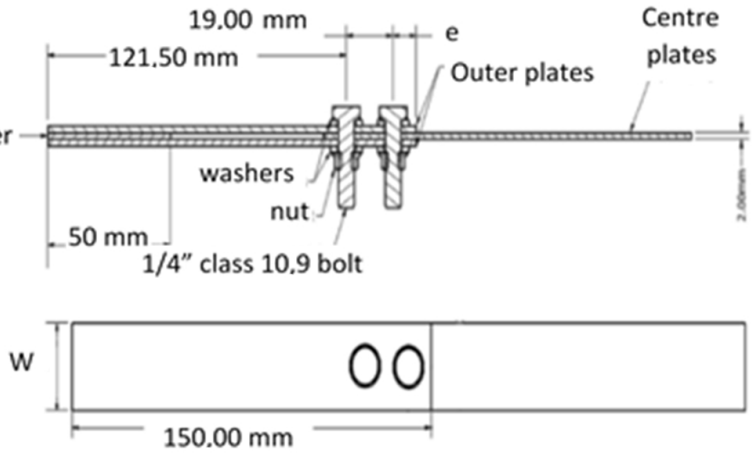
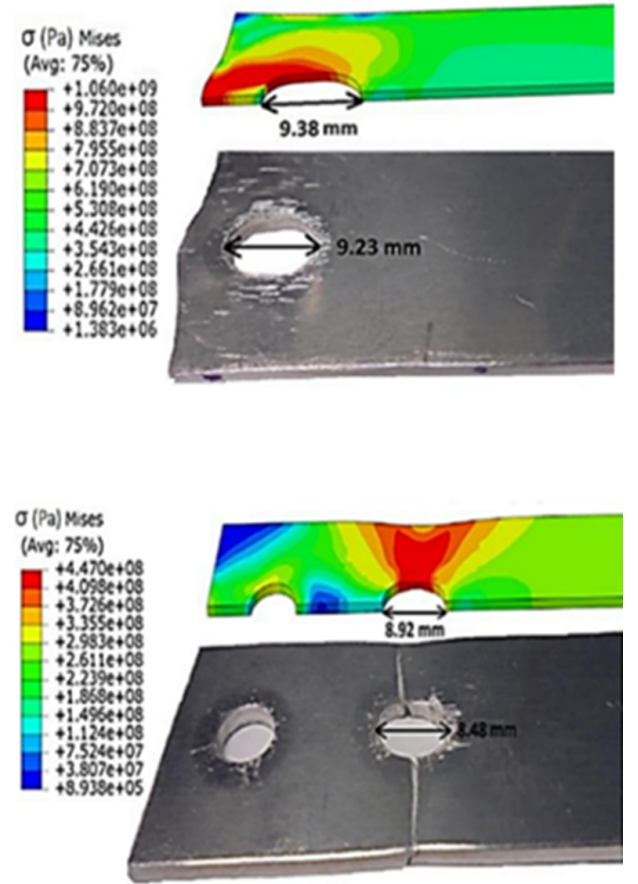

Fig. 9. Tensile test of von Mises stress distribution bolt connection; a). Single bolt connection; b) double bolt connection [10].

\section{Conclusions}

The causes of the failure of the Titen Proto-XX electric car can be described as follows: (1) The use of Aluminum AA 1XXX, which has no weldability. The oxide layer on the surface causes aluminium AA 1XXX does not have good weldability; (2) The cause of failure in the electric vehicle structure Titen Proto-XX lies in the rivet connection. The layout and number of rivet holes have not been studied in terms of crack propagation that will occur. The gap between the plates connected to the rivet needs to be studied further because the gap has a very large stress concentration so that it becomes a crack initiation; (3) Deflection of the electric car Titen Proto-XX is relatively large, so it is necessary to improve the truss design; (4) Analysis of fatigue life needs to be studied further because there are many extreme changes in geometric shapes. 


\section{Acknowledgment}

I wish to extend my full appreciation to all the people who helped me throughout this research. I would also like to thank Prof. Ir. Achmad Subagio, M.Agr., Ph.D and Ir. Khairul Anam, S.T., M.T., Ph.D for the support of the research funding provided through LP2M UNEJ. I would also like to thank the Electric Car Research Group for their discussion and support in providing research topics.

\section{References}

[1] Todd, J., Chen, J., Clogston, F., “Analysis of the Electric Vehicle Industry”, Creating The Clean Energy Economy, International Economic Development Council, 2013.

[2] Sigh, A., Soni, V., Singh, A., "Structural Analysis of Ladder Chassis for Higher Strength", International Journal of Engineering Technology and Advanced Engineering/IJETAE, vol. 4(2), pp. 253-259, 2014.

[3] Li, D., Han, L., Thornton, M., Shergold, M., "Influenced of Rivet to Sheet Edge Distance on Fatigue Strength of Self-Piercing Riveted Alumnium Joints", Materials Science \& Engineering A, 2012.

[4] Denny, J., Veale, K., Adali, S., Leverone, F., "Conceptual design and numerical validation of a composite monocoque solar passenger vehicle chassis", Engineering Science and Technology, an International Journal, pp. 1067-1077. 2018.

[5] Ramesh Kumar, S., Dhandapani, N. V., Parthiban, S., Kamalraj, D., Meganathan, S., Muthuraja, S., "Design and Analysis of Authomotive Chassis Frame Using Finite Element Method", International Journal of Pure and Applied Mathematics, vol. 20, pp. 961-972, 2018,

[6] Mukhopadhay, P., "Alloy Designation, Processing and Use of AA6XXX Series Aluminium Alloys", Review Article, International Scholarly Research Network, ISRN Metalurgy, 2012.

[7] Sire, S., Mayorga, L. G., Plu, B., "Observation of Failure Scenarios in Riveted Assemblies: an Innovative Experimental Strategy", Procedia Engineering, pp. 430436, 2015.

[8] Alabode, M., "Weldability of High Strength Aluminium Alloys", Lappeeranta University of Technology, 2015, Lappeeranta, Finland

[9] Deekhunthod, R., "Weld Quality in Aluminium Alloys”, Uppsala Universiteit, 2014

[10] Fallahnezhad, K., Steele, A., Oskouei, R, H., "Failure Mode Analysis of Aluminium Alloy 2024-T3 in Double-Lap Bolted Joints with Single and Double Fasteners; A Numerical and Experimental Study", Materials, vol 8, pp. 3195-3209, 2015 